\title{
ARTICLES
}

\section{AN OBSERVATIONAL STUDY TO ASSESS THE TECHNIQUES OF INTRAVENOUS MEDICATION THERAPY AMONG STUDENT NURSES OF MATA MOHAN DAI OSWAL COLLEGE OF NURSING, LUDHIANA, PUNJAB.}

\author{
Mrs. Daniel Bency*
}

*Associate Professor, Mata Mohan Dai Oswal College of Nursing, Ludhiana, Punjab, India.

DOI: http://doi.org/10.47211/idcij.2020.v07i03.001

Received $18^{\text {th }}$ May 2020, Accepted $5^{\text {th }}$ June 2020, Available online $10^{\text {th }}$ July 2020.

\begin{abstract}
Preparation and administration of intravenous medication is a crucial clinical activity in the provision of healthcare for hospitalised patient. In healthcare system the medication administration process represents an advanced technology and a complex process. The objectives of the study was to assess the techniques of intravenous medication therapy among the student nurses, to associate the techniques with selected variables and to prepare a guideline regarding proper techniques of intravenous medication therapy to improve the deficit areas of practice among the student nurses. A quantitative approach was adopted to analyse the intravenous medication technique. An observational check list was prepared to assess the techniques of intravenous medication. A non-participatory observation was done to collect the data; three different observations had been done on the same participants for accuracy of data. The study was conducted on B. Sc. $(N)$ and GNM students. A total of 30 participants were selected and 90 observations were done. Data analysis was done by using mean, standard deviation and ' $t$ ' test. Pie, bar diagrams and tables were used to depict the findings. Majority of student nurses (46.6\%) were in the age group of 20 years, $80 \%$ were females, $73.3 \%$ were qualified in the medical stream, $46.6 \%$ were posted in the medicine ward, $76.6 \%$ got information from staff nurses. $60 \%$ of students were having average level of technique regarding intravenous medication and only $40 \%$ were having poor technique and no one was in the category of having good technique. Assembling of articles got rank order 1 and intra procedure steps got a rank order 4 and the mean knowledge score was 27.3. Socio-demographic variables had no effect on intravenous medication except source of information.
\end{abstract}

Key Words: Observational Study, Techniques, Intravenous medication, Student nurses.

\section{ABOUT AUTHOR:}

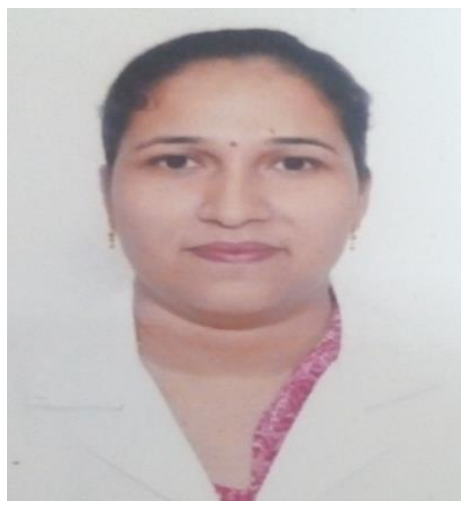

Author Mrs. Bency Daniel is an Associate Professor at Mata Mohan Dai Oswal College of Nursing in Ludhiana, in the Indian state of Punjab. She is a PhD scholar in the Faculty of Nursing Sciences at Baba Farid University of Health Sciences at Faridkot in Punjab. She has presented research papers in various conferences and workshops. 


\section{INTRODUCTION}

Intravenous therapies are administering of liquid substances directly into a vein. The word intravenous simply means "within a vein" but is commonly referred to as IV therapy

Intravenous medication therapy is a therapeutic option used in the treatment of many hospitalised patients. It is complex, potentially dangerous and error prone. The objectives were to assess the drug related problems involved in IV administration of medication and further to develop strategies to reduce and prevent the occurrence of drug related problems during IV medication.

A survey was conducted among nurses in Pantai hospital in Malaysia, and it was found that $75.9 \%$ of nurses had knowledge in caring and maintaining of IV cannula and $24.1 \%$ did not know much and $83.7 \%$ followed the correct practices of care and maintenance of IV cannula.

Medication errors are among the major clinical issues in the healthcare settings. Although IV therapy benefits patients, it also represents a source of risks. The complexity of the procedure, involvement of multiplicity of professionals and services, rapid introduction of new drugs and the diagnostic and therapeutic technologies involved, very frequently result in errors, jeopardising care security and quality and also generates increased cost.

\section{NEED FOR THE STUDY}

Errors in medication administration can affect patient morbidity and mortality. They can also affect patient's families and health care providers indirectly by cost implications, prolonged hospital stay and psychological impact.

A complication that may occur if medication is injected incorrectly includes speed shock caused by rapid injection of a medication. IV sites may show signs of phlebitis or irritation. Injection of medication into a vein may cause inflammation or roughening of the endothelial lining, which can result in thrombus formation which affects the patient's recovery from the actual diagnosis. Student nurses are the roots of nursing profession. They will become tomorrow's health care professionals. So the present study was conducted to observe the techniques used by the students of B.Sc. (N) and GNM while administering intravenous medication and to develop an information booklet to overcome the deficit areas of knowledge and practice.

\section{PROBLEM STATEMENT}

'An Observational Study to Assess the Techniques of Intravenous Medication Therapy among Student Nurses of Mata Mohan Dai Oswal College of Nursing at Ludhiana in Punjab'

\section{OBJECTIVES}

1. To assess the techniques of intravenous medication therapy among student nurses of Mata Mohan Dai Oswal college of Nursing, Ludhiana, Punjab.

2. To associate the techniques with the selected demographic variables like age gender qualification, professional course, area of posting and source of information

3. To prepare a guideline regarding proper techniques of intravenous medication therapy to improve the deficit areas of practice among student nurses.

\section{RESEARCH METHODOLOGY}

Research approach: Quantitative approach

Research design: Non experimental observational design

Setting of the study: The study was conducted at Mohan Dai Oswal Hospital in Ludhiana.

Population: All the student nurses of Mata Mohan Dai Oswal hospital, Ludhiana, Punjab.

Sample and Sampling technique -

Sample: B. Sc. (N) $2^{\text {nd }}$ and $3^{\text {rd }}$ year students and GNM $2^{\text {nd }}$ and $3^{\text {rd }}$ year students of Mata Mohan Dai Oswal College of Nursing in Ludhiana, Punjab.

Sample Size: sample size of present study was 30 student nurses of Mata Mohan Dai Oswal College of Nursing Ludhiana. 


\section{ARTICLES}

Sampling technique: Convenient sampling

Development of tool: Based on the objectives, an observational check list was prepared to assess the techniques of intravenous medication therapy with a view to develop a guideline for the students.

Following steps were selected for preparing the tool -

- Review of related literature

- Preparation of the blue print

- Consultation with guide

- Preparation of final drafts

\section{FINDINGS}

Majority of the students (46.6\%) belonged to the age group 20 years, $(73.3 \%)$ were from the medical stream and $46 \%$ were from B. Sc. (N) 2 nd year. $46.6 \%$ of students were posted in medicine ward and got information regarding intravenous medication techniques from staff nurses.

Table - 1: Levels of Technique of Intravenous medication Therapy

$\mathrm{N}=30$

\begin{tabular}{|l|l|r|r|r|}
\hline Serial No. & Levels of techniques & Score & $\mathbf{n}$ & $\mathbf{n} \%$ \\
\hline a) & Good & $45-60$ & 0 & 0 \\
b) & Average & $30-44$ & 18 & 60 \\
c) & Poor & $0-29$ & 12 & 40 \\
\hline
\end{tabular}

Maximum score $=60$

Minimum score $=0$

Table -1 reveals that majority (60\%) of students were having average level of technique regarding intravenous medication and only $40 \%$ were having poor technique and no one was in the category of having good technique. The mean knowledge score was 27.3.

Analysis of variance and ' $\mathrm{t}$ ' tests were used to find the association between intravenous medication technique and demographic variables and it was found that there was no statistically significant association between technique of intravenous medication therapy of student nurses and their age, gender, academic qualification, professional course pursued, area of posting except their sources of information.

\section{CONCLUSION}

Thus the present study revealed that $60 \%$ of student nurses had average level of techniques and $40 \%$ had poor techniques on intravenous medication therapy. Socio demographic variables were found statistically nonsignificant at $(p \leq .05)$ level except sources of information.

\section{RECOMMENDATIONS}

- Further study can be replicated on a large sample to validate and generalise the findings.

- A comparative study can be conducted on staff nurses of different hospitals.

- A structured teaching module on techniques of intravenous medication can be prepared and tested for its efficacy. 


\section{ARTICLES}

\section{REFERENCE}

1. Aysegul Gunes. Knowledge and practices of nurse concerning potassium administration in a Turkish hospital. Australian Journal of Advanced Nursing. Volume32.No1

2. Sudesh Gyawali. Devendra .S.Rathore. Bhuran KC and Ravi Shankar. Study of status of safe injection practices and knowledge regarding injection safety among primary health care worker in Baglung district Western Nepal. BMC international health and women rights. 2013,13:3.

3. Mostafa A abolfotouh. et al. Prospective study of incidence and predictors of peripheral intravenous catheter induced complication. Journal of Therapeutics and clinical risk management. Volume10. 203-6

4. Dr. Ahmad Nizal Mohd Ghazali. Nurses knowledge and practice towards care and maintenance of peripheral intravenous cannulation. Available at http://www.Research gate.net//publication.

5. Vijayakumar A, Sharon E.V. A clinical study on drug related problems associated with intravenous drug administration. Journal of basic clinical pharmacology.2014.

6. Allan EL, Barker KN. Fundamentals of Medication error research. Am J Hosp Pharm. 1990.47:555-71. 